Pemikiran Pendidikan Islam Menurut...

\title{
PEMIKIRAN PENDIDIKAN ISLAM MENURUT
}

\author{
K.H. HASYIM ASY'ARI
}

\author{
Dhevin M.Q Agus Puspita W \\ Fakultas Tarbiyah IAI Al-Falah As-sunniyyah Kencong Jember \\ dheinmq@yahoo.co.id
}

\begin{abstract}
KH Hasyim Asy'ari is a scholar who was born from an elite family of kiai in the Jombang area, he had studied at various boarding schools in Java before continuing his education to the Hijaz land. Then he returned to Indonesia and established the Tebuireng Jombang boarding school which is famous for its hadith science. The depth of knowledge, and his thinking in education is very brilliant, so he got the title "Hadratus Shaykh" which means "Mr. Professor". Hasyim Asy'ari's thoughts in the field of Education are more viewed in terms of ethics in education. which relates to the principles of the implementation of education and psychology in the world of education which then gave birth to an effective personality for students and teaching. One of Hasyim Asy'ari's monumental works is the book entitled Adab al Alim wa al Muta'allim fima Yahtaj ilah al Muta'alim fi Ahuwal Ta'allum wama Yataqaff al Mu'allim fi Maqamat Ta'limih, In that book he summarizes his thoughts about Islamic education into eight points, namely: a) The virtue of knowledge and the importance of teaching and learning. b) Ethics that must be considered in teaching and learning, c) Ethics of a student to the teacher, d) Ethics of a student regarding lessons and things that must be guided by the teacher, e) Ethics that must be guided by a teacher, f) Ethics of the teacher when and will teach, g) The ethics of the teacher towards his students, h) The ethics of books, tools for getting lessons and things related to it. Furthermore, in the eight theories about education are summarized in thethree concepts first, the significance of education. second, the tasks and responsibilities of students. Third, the duties and responsibilities of the teacher.
\end{abstract}

Keywords: Hasyim Asy'ari, Islamic Education

\begin{abstract}
Abstrak
K.H. Hasyim Asy'ari merupakan ulama' yang lahir dari keluarga elit kiai di daerah Jombang, beliau pernah belajar di berbagai pesantren di pulau Jawa sebelum melanjutkan pendidikan ke tanah Hijaz. Kemudian kembali ke Indonesia dan mendirikan pesantren Tebuireng Jombang yang terkenal dengan ilmu haditsnya. Kedalaman ilmu, dan pemikirannya dalam pendidikan sangat brilian, sehingga beliau mendapatkan gelar "Hadratus Syekh" yang berarti "Tuan Guru Besar". Pemikiran Hasyim Asy'ari dalam bidang Pendidikan lebih banyak ditinjau dari segi etika dalam pendidikan. yang kaitannya dengan prinsip-prinsip pelaksanaan pendidikan serta psikologi dalam dunia pendidikan yang kemudian melahirkan kepribadian yang efektif bagi pelajar dan
\end{abstract}

Falasifa, Vol. 10 Nomor 2 September 2019| 50 
mengajar. Salah satu karya monumental Hasyim Asy'ari adalah kitab yang berjudul Adab al Alim wa al Muta'allim fima Yahtaj ilah al Muta'alim fi Ahuwal Ta'allum wama Yataqaff al Mu'allim fi Maqamat Ta'limih, Dalam kitab tersebut beliau merangkum pemikirannya tentang pendidikan Islam kedalam delapan poin, yaitu : a) Keutamaan ilmu dan keutamaan belajar mengajar. b) Etika yang harus diperhatikan dalam belajar mengajar, c) Etika seorang murid kepada guru, d) Etika seorang murid terhadap pelajaran dan hal-hal yang harus dipedomi berasama guru, e) Etika yang harus dipedomi seorang guru, f) Etika guru ketika dan akan mengajar, g) Etika guru terhadap murid-murid nya, h) Etika terhadap buku, alat untuk memperoleh pelajaran dan hal-hal yang berkaitannya dengannya. Lebih lanjut dalam kedelapan teori tentang pendidikan tersebut di rangkum dalam tiga konsep yang pertama, signifikansi pendidikan. kedua, tugas dan tanggung jawab murid. Ketiga, tugas dan tanggung jawab guru.

Kata Kunci: Hasyim Asy'ari, Pendidikan Islam

\section{PENDAHULUAN}

\section{A. Latar Belakang}

Para ulama memiliki peranan besar memberikan pengajaran kepada seluruh masyarakat di manapun mereka berada, tidak terlepas dengan Indonesia. Di mulai semenjak Islam masuk ke Indonesia abad 7 Masehi $^{1}$ kebenaran ini diperkuat dengan lahirnya tokoh tokoh ulama yang menyebarkan Islam keseluruh tanah Jawa.

Salah satu sosok ulama yang berperan aktif dalam mensyiarkan Islam di pulau Jawa adalah K.H. Hasyim Asy’ari. Beliau merupakan pendiri organisasi Islam terbesar di Indonesia yakni Nahdlatul Ulama. ketokohan dan keharuman nama beliau bukan hanya karena aktivitas dakwah sebagai pendiri NU, melainkan juga karena beliau termasuk pemikir dan pembaharu Pendidikan Islam yang ada di Indonesia. $^{2}$

K.H. Hasyim Asy’ari merupakan ulama' yang lahir dari keluarga elit kiai di daerah Jombang, beliau pernah belajar di berbagai pesantren di pulau Jawa sebelum melanjutkan pendidikan ke tanah Hijaz. Kemudian kembali ke Indonesia dan

\footnotetext{
1 Pendapat ini didukung oleh Hamka, dengan alasan berita Cina yang mengisahkan kedatangan utusan raja Ta Cheh kepada ratu Sima. Adapun raja Tah Cheh menurut Hamka; Raja Arab dan khalifah saat itu adalah Mu'awiyah bin Abi Sufyan. Peristiwa itu terjadi pada saat Mu'awiyah melaksanakan pembangunan kembali armada Islam. Pendapat ini diperkuat dengan beberapa bukti yang berupa Makam (batu nisan), masjid, ragam hias dan tata kota. Lih. Drs. H.M. Darori Amin, MA, Islam dan Budaya Jawa, (Yogyakarta: Gama Media, 2000), hlm. 28.

2 Zamarkhasyi Dhofier, Tradisi Pesantren (Jakarta, LP3ES, 1992) h. 58.
}

Falasifa, Vol. 10 Nomor 2 September 2019| 51 
Dhevin M.Q Agus Puspita W

mendirikan pesantren Tebuireng Jombang yang terkenal dengan ilmu haditsnya. Kedalaman ilmu, dan pemikirannya dalam pendidikan sangat brilian, sampaisampai para kiai di Jawa memberinya gelar "Hadratus Syekh" yang berarti "Tuan Guru Besar". ${ }^{3}$

Sejak pertengahan abad ke-19 banyak para remaja muda Indonesia yang belajar di Mekkah dan Madinah, untuk menekuni agama Islam. Realitas ini amat memungkinkan bagi mereka yang belajar di sana, untuk mencapai tingkat pengetahuan yang lebih luas serta pandangan yang lebih terbuka mengenai sosok Islam.

Di antara mereka yang berhasil gemilang di dalam mengkaji Islam adalah Syekh Nawawi al Bantani dari Banten Jawa Barat, Syekh Mahfudz Attarmisi dari Pacitan Jawa Timur, serta Syekh Ahmad Chatib Sambas dari Kalimantan. Kesuksesan mereka ini ditandai dengan kedalaman ilmu yang mereka miliki, yang bukan saja diakui oleh masyarakat Tanah Suci Mekkah melainkan juga diakui oleh masyarakat Arab pada umumnya. ${ }^{4}$

Generasi berikutnya yang juga merupakan murid langsung dari mereka antara lain Muhammad Hasyim Asy'ari yang terkenal dengan panggilan mbah Hasyim. Hasyim Asy'ari yang haus akan ilmu pengetahuan selalu melakukan kegiatan belajar dari pesantren satu ke pesantren lain di daerah Jawa hingga pada akhirnya belajar ke Mekkah kurang lebih 7 tahun. Sekembalinya dari Makkah beliau menetap didaerah Jombang dan istiqomah melakukan dakwah serta pengajaran Islam hingga pada akhirnya mampu melahirkan ulama-ulama terkemuka di Jawa yang nyaris seluruhnya menjadi pendiri dan pengasuh pesantren di daerahnya masing-masing.

Pemikiran Hasyim Asy'ari dalam bidang Pendidikan lebih banyak ditinjau dari segi etika dalam pendidikan. Etika dalam dunia pendidikan, banyak disinggung dalam kaitannya dengan prinsip-prinsip pelaksanaan pendidikan serta psikologi

3 Dewan Redaksi,Ensiklopedia Islam, (Jakarta, PT.Ichtiar Baru Van Hoeve,1997).h.309

${ }^{4}$ Khoirul Fathoni \&Muhammad Zen, NU Pasca Khittah, (Yogyakarta: Media Widia Mandala, 1992) h.25

Falasifa, Vol. 10 Nomor 2 September 2019| 52 
Pemikiran Pendidikan Islam Menurut..

dalam dunia pendidikan yang kemudian melahirkan kepribadian yang efektif bagi pelajar dan mengajar.

Pemikiran Hasyim Asy’ari sendiri dalam pendidikan boleh jadi diwarnai dengan keahliannya dalam bidang hadits, bidang tasawuf dan fiqh. Serta didorong pula oleh situasi pendidikan yang ada pada saat itu, yang telah mengalami

perubahan dan perkembangan yang sangat pesat, dari kebiasaan lama atau tradisional dengan sistem pendidikan salafi yang sudah mapan ke dalam bentuk baru atau modern dengan sistem khalafi akibat pengaruh sistem pendidikan Belanda yang diterapkan di Indonesia.

\section{B. PEMbahasan}

\section{Riwayat Hidup K.H. Hasyim Asy’ari}

Hasyim Asy'ari lahir di desa Nggedang sekitar dua kilometer sebelah Timur Kabupaten Jombang, Jawa Timur. Pada hari Selasa kliwon, tanggal 24 Dzulhijjah 1287 atau bertepatan tanggal 14 Pebruari 1871 M. Nama lengkapnya adalah Muhammad Hasyim ibn Asy'ari ibn Abd. Al Wahid ibn Abd. Al Halim yang mempunyai gelar Pangeran Bona ibn Abd. Al Rahman Ibn Abd. Al Aziz Abd. Al Fatah ibn Maulana Ushak dari Raden Ain al Yaqin yang disebut dengan Sunan Giri. ${ }^{5}$ Dipercaya pula bahwa mereka adalah keturunan raja Muslim Jawa, Jaka Tinggir dan raja Hindu Majapahit, Brawijaya VI. Jadi Hasyim Asy'ari juga dipercaya keturunan dari keluarga bangsawan. ${ }^{6}$

Ibunya, Halimah adalah putri dari kiai Ustman, guru Asy'ari sewaktu mondok di pesantren. Jadi, ayah Hasyim adalah santri pandai yang mondok di kiai Ustman, hingga akhirnya karena kepandaian dan akhlak luhur yang dimiliki, ia diambil menjadi menantu dan dinikahkan dengan Halimah. Sementara kiai Ustman sendiri adalah kiai terkenal dan juga pendiri pesantren Gedang yang didirikannya pada akhir abad ke-19. Hasyim Asy'ari adalah anak ketiga dari sepuluh bersaudara, yaitu Nafiah, Ahmad Saleh, Radiah, Hassan, Anis, Fatanah, Maimunah, Maksum, Nahrawi, dan Adnan.

\footnotetext{
5 Samsul Nizar, Filsafat Pendidikan Islam, (jakarta: ciputat Press, 2002).h. 152

6 lbid. H. 67
} 
Dhevin M.Q Agus Puspita W

Dari lingkungan pesantren inilah Hasyim Asy’ari mendapat didikan awal tentang berbagai hal yang berkaitan dengan ke-Islaman. Hingga usia lima tahun, Hasyim mendapat tempaan dan asuhan orangtua dan kakeknya di pesantren Gedang. Mula-mula ia belajar pada ayahnya sendiri, lalu bergabung bersama santri lain untuk memperdalam ilmu agama dan pesantren itu para santri mengamalkan ajaran agama dan belajar berbagai cabang ilmu agama Islam.

Suasana inilah yang mampu mempengaruhi karakter Hasyim Asy’ari yang sederhana dan rajin belajar. Minat bacanya sangat tinggi, hingga yang dibaca bukan hanya buku-buku pelajaran dengan literatur-leteratur Islam, tetapi juga buku-buku lain dan umum.

Pada tahun 1876, ketika Hasyim Asy'ari berumur 6 tahun, ayahnya mendirikan pesantren di sebelah Selatan Jombang, suatu pengalaman yang di masa mendatang mempengaruhi beliau untuk kemudian mendirikan pesantren sendiri. Dari sini dapat dilihat bahwa kehidupan masa kecilnya di lingkungan pesantren berperan besar dalam pembentukan wataknya yang haus ilmu pengetahuan dan kepeduliannya pada pelaksanaan ajaran-ajaran agama dengan baik.

Menurut penuturan ibunya, tanda kecerdasan dan ketokohan Hasyim Asy'ari sudah tampak saat ia masih berada dalam kandungan. Di samping masa kandung yang lebih lama dari umumnya kandungan, ibunya juga pernah bermimpi melihat bulan jatuh dari langit ke dalam kandungannya. ${ }^{7}$ Mimpi tersebut kiranya bukanlah isapan jempol dan kembang tidur belaka, sebab ternyata tercatat dalam sejarah, bahwa pada usianya yang masih sangat muda, 13 tahun, Hasyim Asy'ari sudah berani menjadi guru pengganti (badal) di pesantren untuk mengajar santrisantri yang tidak jarang lebih tua dari umurnya sendiri. Serta di kemudian hari kita saksikan sepak terjang dan perjuangannya di berbagai bidang.

Pada usia muda Hasyim Asy'ari mulai melakukan pengembaraan ke berbagai pesantren di luar daerah Jombang. Pada awalnya, ia menjadi santri di pesantren Wonokojo di Probolinggo, kemudian berpindah ke pesantren Langitan, Tuban. Dari Langitan santri yang cerdas tersebut berpindah lagi ke pesantren Trenggilis, hingga pesantren Kademangan Bangkalan, di Madura sebuah pesantren yang diasuh kyai Khalil. Terakhir sebelum belajar ke Mekkah, ia sempat nyantri dan tinggal lama di pesantren Siwalan Panji, Sidoarjo, di bawah asuhan kiai Ya'qub,

${ }^{7}$ Lathiful khuluq, kebangkitan sosial. H. 19

Falasifa, Vol. 10 Nomor 2 September $2019 \mid 54$ 
sampai akhirnya diambil menantu oleh kiai Ya'qub, dinikahkan dengan anaknya yang bernama Khadijah tahun 1892.

Tidak berapa lama kemudian ia beserta isteri dan mertuanya berangkat haji ke Mekkah yang dilanjutkan dengan belajar di sana. Modal pengetahuan agama selama nyantri di tanah air memudahkan Hasyim memahami pelajaran selama di Mekkah. Akan tetapi setelah isterinya meninggal karena melahirkan, menyebabkannya kembali ke tanah air.

Semangat belajar yang tinggi akan ilmu pengetahuan membawa Hasyim Asy'ari berangkat lagi ke tanah suci Mekkah tahun berikutnya. Beliau menetap di sana kurang lebih tujuh tahun dan berguru pada sejumlah ulama, di antaranya Syaikh Ahmad Amin al Aththar, Sayyid Sultan ibn Hasyim, Sayyid Abdullah al Zawawi, Syaikh Shaleh Bafadhal dan Syaikh Sultan Hasyim Dagastani. ${ }^{8}$

Minatnya begitu tinggi terhadap ilmu pengetahuan, terutama ilmu hadits dan tasawuf. Hal ini yang membuat Hasyim di kemudian hari senang mengajarkan hadits dan tasawuf. Pada masa-masa akhir di Mekkah beliau sempat memberikan pengajaran kepada orang lain yang memerlukan bimbingannya, dan ini yang menjadi bekal tersendri yang kemudian hari diteruskan setelah kembali ke tanah air. 9

Pada tahun 1899/1900 ia kembali ke Indonesia dan mengajar di pesantren ayahnya dan kakeknya, hingga berlangsung beberapa waktu. Masa berikutnya Hasyim menikah lagi dengan putri kiai Ramli dari Kemuning (Kediri) yang bernama Nafiah, setelah sekian lama menduda. Mulai itu beliau diminta membantu mengajar di pesantren mertuanya di Kemuning, baru kemudian mendirikan pesantren sendiri di daerah sekitar Cukir, pesantren Tebuireng di Jombang, pada tanggal 6 Pebruari 1906. Pesantren yang baru didirikan tersebut tidak berapa lama berkembang menjadi pesantren yang terkenal di Nusantara, dan menjadi tempat menggodok kader-kader ulama wilayah Jawa dan sekitarnya.

Sejak masih di pondok, ia telah dipercaya untuk membimbing dan mengajar santri baru. Ketika di Mekkah, ia juga sempat mengajar. Demikian pula ketika kembali ke tanah air, diabdikannya seluruh hidupnya untuk agama dan ilmu. Kehidupannya banyak tersita untuk para santrinya. Ia terkenal dengan disiplin waktu (istiqamah). Hasyim Asy'ari meninggal pada tanggal 7 Ramadhan 1366 H

\footnotetext{
${ }^{8}$ Lathiful Khuluq, Kebangkitan Ulama, Biografi K.H Hasyim Asy’ari (Yogyakarta: LKIS,2000), h. 14

${ }^{9}$ Maksum Machfoedz, Kebangkitan Ulama dan Bangkitnya Ulama, (Surabaya: Yayasan Kesatuan Umat, 1982).h. 75
}

Falasifa, Vol. 10 Nomor 2 September 2019| 55 
Dhevin M.QAgus Puspita W

bertepatan dengan 25 Juli 1947 M di Tebuireng Jombang dalam usia 79 tahun, karena tekanan darah tinggi dan beliau dimakamkan di daerah tebuireng Jombang yang sampai saat ini banyak para muslim yang menziarahi. ${ }^{10}$

\section{Karya K.H. Hasyim Asy'ari}

Tidak banyak para ulama dari kalangan tradisional yang menulis buku. Akan tetapi tidak demikian dengan Hasyim Asy'ari, tidak kurang dari sepuluh kitab disusunnya, antara lain: ${ }^{11}$

a) Adab al Alim wa al Muta'allim fima Yahtaj ilah al Muta'alim fi Ahuwal Ta'allum wa ma Yataqaff al Mu'allim fi Maqamat Ta'limih. Tatakrama pengajar dan pelajar. Berisi tentang etika bagi para pelajar dan pendidik, merupakan resume dari Adab al-Mu'allim karya Syekh Muhammad bin Sahnun (w.256 H/871 M); Ta'lim al-Muta'allim fi Thariq at-Ta'allum karya Syeikh Burhanuddin al-Zarnuji (w.591 H); dan Tadzkirat al-Saml wa alMutakallim fi Adab al-'Alim wa al-Muta'allim karya Syeikh Ibn Jama'ah. Memuat 8 bab, diterbitkan oleh Maktabah at-Turats al-Islamy Tebuireng. Di akhir kitab terdapat banyak pengantar dari para ulama, seperti: Syeikh Sa'id bin Muhammad al-Yamani (pengajar di Masjidil Haram, bermadzhab Syafii), Syeikh Abdul Hamid Sinbal Hadidi (guru besar di Masjidil Haram, bermadzhab Hanafi), Syeikh Hasan bin Said al-Yamani (Guru besar Masjidil Haram), dan Syeikh Muhammad 'Ali bin Sa'id al-Yamani.

b) Al Risalat al Jamiat, Sharh fiha Ahmaal al Mauta wa Asirath al sa'at ma'bayan Mafhum al Sunnah wa al Bid'ah. . Risalah Ahl Sunnah Wal Jama'ah tentang hadis-hadis yang menjelaskan kematian, tanda-tanda hari kiamat, serta menjelaskan sunnah dan bid'ah. Berisi 9 pasal.

c) Ziyadat Ta'liqat, Radda fiha Mandhumat al Syaikh “Abd Allah bin Yasin al Fasurani Allati Bihujubiha "ala Ahl Jam'iyyah Nahdhatul Ulama. Catatan seputar nadzam Syeikh Abdullah bin Yasin Pasuruan. Berisi polemik antara Kiai Hasyim dan Syeikh Abdullah bin Yasir. Di dalamnya juga terdapat banyak pasal berbahasa Jawa dan merupakan fatwa Kiai Hasyim yang pernah dimuat di Majalah Nahdhatoel Oelama'. Tebal 144 halaman.

10 Lathiful Khuluq, Kebangkitan Ulama, Biografi K.H Hasyim Asy'ari (Yogyakarta: LKIS,2000), h. 16

11 Ibid. h.18

Falasifa, Vol. 10 Nomor 2 September $2019 \mid 56$ 
d) Al Tanbihat al Wajibat liman Yashna al Maulid al Munkarat Peringatanperingatan wajib bagi penyelenggara kegiatan maulid yang dicampuri dengan kemungkaran. Ditulis berdasarkan kejadian yang pernah dilihat pada malam Senin, 25 Rabi' al-Awwal 1355 H., saat para santri di salah satu pesantren sedang merayakan Maulid Nabi yang diiringi dengan perbuatan mungkar, seperti bercampurnya laki-laki dan perempuan, permainan yang menyerupai judi, senda gurau, dll. Pada halaman pertama terdapat pengantar dari tim lajnah ulama al-Azhar, Mesir. Selesai ditulis pada 14 Rabi' at-Tsani 1355 H., terdiri dari 15 bab setebal 63 halaman, dicetak oleh Maktabah atTurats al-Islamy Tebuireng, cetakan pertama tahun $1415 \mathrm{H}$.

e) Al Risalat al Jamiat, Sharh fiha Ahmaal al Mauta wa Asirath al sa'at ma'bayan Mafhum al Sunnah wa al Bid'ah. . Risalah Ahl Sunnah Wal Jama'ah tentang hadis-hadis yang menjelaskan kematian, tanda-tanda hari kiamat, serta menjelaskan sunnah dan bid'ah. Berisi 9 pasal.

f) Al Nur al Mubin fi Mahabbah Sayyid al Mursalin, bain fihi Ma'na al Mahabbah Libasul Allah wa ma Yata'allaq biha Man Ittiba'iha wa Ihya al Sunnahih. Cahaya yang jelas menerangkan cinta kepada pemimpin para rasul. Berisi dasar kewajiban seorang muslim untuk beriman, mentaati, meneladani, dan mencintai Nabi Muhammad SAW. Tebal 87 halaman, memuat biografi singkat Nabi SAW mulai lahir hingga wafat, dan menjelaskan mu'jizat shalawat, ziarah, wasilah, serta syafaat. Selesai ditulis pada 25 Sya'ban 1346 H., terdiri dari 29 bab.

g) Hasyiyah 'ala Fath al Rahman bi Syarth Risalat al Wali Ruslan li Syaikh al Islam Zakaria al Ansyari.

h) Al Duur al Muntasirah fi Masail al Tiss'I Asyrat, Sharth fiha Masalat al Thariqah wa al Wilayah wa ma Yata'allq bihima min al Umur al Muhimmah li ahl thariqah. Mutiara yang memancar dalam menerangkan 19 masalah. Berisi kajian tentang wali dan thariqah dalam bentuk tanya-jawab sebanyak 19 masalah. Tahun 1970-an kitab ini diterjemahkan oleh Dr. KH. Thalhah Mansoer atas perintah KH. M. Yusuf Hasyim, dierbitkan oleh percetakan Menara Kudus. Di dalamnya memuat catatan editor setebal xxxiii halaman. Sedangkan kitab aslinya dimulai dari halaman 1 sampai halaman 29.

i) Al Tibyan fi al Nahy 'an Muqathi'ah al Ihwan, bain fih Ahammiyat Shillat al Rahim wa Dhurrar qatha'iha. Berisi tentang tata cara menjalin silaturrahim, bahaya dan pentingnya interaksi sosial. Tebal 17 halaman, selesai ditulis hari 
Dhevin M.QAgus Puspita W

Senin, 20 Syawal 1360 H., penerbit Maktabah Al-Turats Al-Islami Ma'had Tebuireng.

j) Al Risalah al Tauhidiyah, wahiya Risalah Shaghirat fi Bayan 'Aqidah Ahl Sunnah wa al Jamaah.

k) Al Walaid fi Bayan ma Yajib min al'Aqaid.

1) Al-Risalah fi at-Tasawwuf. Menerangkan tentang tashawuf; penjelasan tentang ma'rifat, syariat, thariqah, dan haqiqat. Ditulis dengan bahasa Jawa, dicetak bersama kitab al-Risalah fi al-'Aqaid.

m) Al-Risalah fi al-'Aqaid. Berbahasa Jawa, berisi kajian tauhid, pernah dicetak oleh Maktabah an-Nabhaniyah al-Kubra Surabaya, bekerja sama dengan percetakan Musthafa al-Babi al-Halabi Mesir tahun 1356 H./1937M. Dicetak bersama kitab Kiai Hasyim lainnya yang berjudul Risalah fi at-Tashawwuf serta dua kitab lainnya karya seorang ulama dari Tuban. Risalah ini ditashhih oleh syeikh Fahmi Ja'far al-Jawi dan Syeikh Ahmad Said 'Ali (alAzhar). Selelai ditash-hih pada hari Kamis, 26 Syawal 1356 H/30 Desember 1937 M.

Di samping bergerak dalam dunia pendidikan, Hasyim Asy’ari menjadi perintis dan pendiri organisasi kemasyarakatan NU (Nahdhatul Ulama), sekaligus sebagai Rais Akbar. Pada bagian lain, ia juga bersikap konfrontatif terhadap penjajah Belanda. Ia, misalnya menolak menerima penghargaan dari pemerintah Belanda. Bahkan pada saat revolusi fisik, ia menyerukan jihad melawan penjajah dan menolak bekerja sama dengannya. Sementara pada masa penjajahan Jepang, ia sempat ditahan dan diasingkan ke Mojokerta. ${ }^{12}$

\section{Pemikiran K.H. Hasyim Asy'ari dalam Pendidikan Islam}

Hasyim Asy'ari yang dilahirkan dan dibesarkan dalam lingkungan pesantren, serta banyak menuntut ilmu dan berkecimpung secara langsung di dalamnya, di lingkungan pendidikan agama Islam khususnya. Dan semua yang dialami dan dirasakan beliau selama itu menjadi pengalaman yang dapat mempengaruhi pola pikir dan pandangannya dalam masalah-masalah pendidikan.

Salah satu karya monumental Hasyim Asy’ari seperti yang dikutip oleh samsul Nizar dalam bukunya filsafat pendidikan Islam adalah kitabnya yang

12 Suwendi, Sejarah E Pemikiran Pendidikan Islam (Jakarta: PT. Raja Grafindo Persada, 2004), h. 141 Falasifa, Vol. 10 Nomor 2 September $2019 \mid 58$ 
Pemikiran Pendidikan Islam Menurut..

berjudul Adab al Alim wa al Muta'allim fima Yahtaj ilah al Muta'alim fi Ahuwal Ta'allum wama Yataqaff al Mu'allim fi Maqamat Ta'limih, ${ }^{13}$ Dalam kitab tersebut beliau merangkum pemikirannya tentang pendidikan Islam kedalam delapan poin, yaitu :

a) Keutamaan ilmu dan keutamaan belajar mengajar

b) Etika yang harus diperhatikan dalam belajar mengajar

c) Etika seorang murid kepada guru

d) Etika seorang murid terhadap pelajaran dan hal-hal yang harus dipedomi berasama guru

e) Etika yang harus dipedomi seorang guru

f) Etika guru ketika dan akan mengajar

g) Etika guru terhadap murid-murid nya

h) Etika terhadap buku, alat untuk memperoleh pelajaran dan hal-hal yang berkaitannya dengannya. ${ }^{14}$

Dari delapan pokok pemikiran di atas, Hasyim Asy’ari membaginya kembali kedalam tiga kelompok, yaitu : Signifikansi Pendidikan, Tugas dan tanggung jawab seorang murid, Tugas dan tanggung jawab seorang guru. ${ }^{15}$ Pada dasarnya, ketiga kelompok pemikiran tersebut adalah hasil integralisasi dari delapan pokok pendidikan yang dituangkan oleh KH. Hasyim Asy’ari.

1) Sigifikansi Pendidikan

Dalam membahas masalah ini, KH.Hasyim Asy'ari mengorientasikan pendapatnya berdasarkan alqur'an dan Al-Hadits. Sebagai contohnya ialah beliau mengambil pemikiran pendidikan tentang keutamaan menuntut ilmu dan keutamaan bagi yang menuntut ilmu dari surat Al-Mujadilah ayat 11 yang kemudian beliau uraikan secara singkat dan jelas. Misalnya beliau menyebutkan bahwa keutamaan yang paling utama dalam menuntut ilmu adalah mengamalkan apa yang telah dituntut. Secara langsung beliau akan menjelaskan maksud dari perkataan itu, yaitu

${ }^{13}$ Samsul Nizar, Filsafat Pendidikan Islam, h. 87

${ }^{14} \mathrm{Ibid}$, ...h. 102

${ }^{15}$ Samsun Nizar, Filsafat Pendidikan Islam,.... H. 101

Falasifa, Vol. 10 Nomor 2 September 2019| 59 


\section{Dhevin M.Q Agus Puspita W}

agar seseorang tidak melupakan ilmu yang telah dimilikinya dan bermanfaat bagi kehidupannya di akherat kelak.

KH. Hasyim Asy'ari menyebutkan bahwa dalam menuntut ilmu harus memperhatikan dua hal pokok selain dari keimanan dan tauhid. Dua hal pokok tersebut adalah : pertama, bagi seorang peserta didik hendaknya ia memiliki niat yang suci untuk menuntut ilmu, jangan sekali-kali berniat untuk hal-hal yang bersifat duniawi dan jangan melecehkan atau menyepelekannya. Kedua, bagi guru dalam mengajarkan ilmu hendaknya meluruskan niatnya terlebih dahulu tidak semata-mata hanya mengharapkan materi, disamping itu hendaknya apa yang diajarkan sesuai dengan apa yang diperbuat. ${ }^{16}$

Hasyim Asy'ari juga menekankan bahwa belajar bukanlah semata-mata hanya untuk menghilangkan kebodohan, namun untuk mencari ridho Allah yang mengantarkan manusia untuk mendapatkan kebahagiaan dunia dan akherat. Kareba itu hendaknya belajar diniatkan untuk mengembangkan dan melestarikan nilai-nilai islam bukan hanya semata-mata menjadi alat penyebrangan untuk mendapatkan meteri yang berlimpah.

2) Tugas dan Tanggung Jawab Murid

Murid sebagai peserta didik memiliki tugas dan tanggung jawab berupa etika dalam menuntut ilmu, yaitu :

a. Etika yang harus diperhatikan dalam belajar yaitu: membersihkan hati dari berbagai gangguan keimanan dan keduniawian, membersihkan niat, tidak menunda-nunda kesempatan belajar, bersabar dan qonaah terhadap segala macam pemberian dan cobaan, pandai mengatur waktu, menyederhanakan makan dan minum, bersikap hati-hati atau wara', menghindari makanan dan minuman yang menyebabkan kemalasan yang pada akhirnya menimbulkan kebodohan, menyediakan waktu tidur selagi tidak merusak kesehatan, meninggalkan kurang faedah (hal-hal yang

\footnotetext{
${ }^{16}$ Suwendi, Sejarah \& Pemikiran Pendidikan Islam (Jakarta: PT. Raja Grafindo Persada, 2004), h. 74
} 
Pemikiran Pendidikan Islam Menurut..

kurang berguna bagi perkembangan diri). ${ }^{17}$ Dalam hal ini tidak dibenarkan ketika seorang yang menuntut ilmu hanya menekankan pada hal-hal yang bersifat rohaniah atau duniawiah saja, karena keduanya adalah penting.

b. Etika Seorang Murid Terhadap Guru yaitu : hendaknya selalu memperhatikan dan mendengarkan apa yang dijelaskan atau dikatakan oleh guru, memilih guru yang wara' artinya orang yang selalu berhati-hati dalam bertindak disamping profesionalisme, mengikuti jejak guru yang baik, bersabar terhadap kekerasan guru, berkunjung kepada guru pada tempatnya atau mintalah izin terlebih dahulu kalau harus memaksa keadaan pada bukan tempatnya, duduklah yang rapi dan sopan ketika berhadapan dengan guru, berbicaralah dengan sopan dan lemah lembut, dengarkan segala fatwanya, jangan sekali-kali menyela ketika sedang menjelaskan, dan gunakan anggota kanan bila menyerahkan sesuatu kepadanya. ${ }^{18}$

c. Etika Murid Terhadap Pelajaran yaitu: memperhatikan ilmu yang bersifat fardhu 'ain untuk dipelajari, harus mempelajari ilmu-ilmu yang mendukung ilmu-ilmu fardhu 'ain, berhati-hati dalam menanggapi ikhtilaf para ulama, mendiskusikan atau menyetorkan apa yang telah ia pelajari pada orang yang dipercayainya, senantiasa menganalisa, menyimak dan meneliti ilmu, pancangkan cita-cita yang tinggi, bergaulah dengan orang berilmu lebih tinggi (intelektual), ucapkan bila sampai ditempat majlis ta'lim (tempat belajar, sekolah, pesantren, dan lain-lain), bila terdapat halhal yang belum diketahui hendaknya ditanyakan, bila kebetulan bersamaan banyak teman, jangan mendahului antrian bila tidak mendapatkan izin, kemanapun kita pergi kemanapun kita berada jangan lupa bawa catatan, pelajari pelajaran yang telah diajarkan dengan

\footnotetext{
17 Samsul Nizar, Filsafat Pendidikan Islam, .....h. 132

18Samsul Nizar, Filsafat Pendidikan Islam, ... h. 147
}

Falasifa, Vol. 10 Nomor 2 September 2019| 61 


\section{Dhevin M.Q Agus Puspita W}

continue (istiqomah) dan terakhir tanamkan rasa semangat dalam belajar. 19

3) Tugas dan Tanggung Jawab Guru

Dalam dunia pendidikan tidak hanya seorang murid yang memiliki tanggung jawab. Namun seorang guru juga memiliki tanggung jawab yang hampir serupa dengan murid, yaitu :

a. Etika Seorang Guru

Seorang guru dalam menyampaikan ilmu pada peserta didik harus memiliki etika sebagai berikut yaitu: selalu mendekatkan diri kepada Allah, senantiasa takut kepada Allah, senantiasa bersikap tenang, senantiasa berhati-hati, senantiasa tawadhu' dan khusu', mengadukan segala persoalannya kepada Allah SWT, tidak menggunakan ilmunya untuk keduniawian saja, tidak selalu memanjakan anak didik, berlaku zuhud dalam kehidupan dunia, menghindari berusaha dalam hal-hal yang rendah, menghindari tempat-tempat yang kotor atau maksiat, mengamalkan sunnah nabi, mengistiqomahkan membaca al-qur'an, bersikap ramah, ceria, dan suka menebarkan salam, membersihkan diri dari perbuatan yang tidak disukai Allah, menumbuhkan semangat untuk mengembangkan dan, menambah ilmu pengetahuan, tidak menyalahgunakan ilmu dengan menyombongkannya, dan membiasakan diri menulis, mengarang dan meringkas. ${ }^{20}$

b. Etika Guru dalam mengajar

Seorang guru ketika mengajar dan hendak mengajar hendaknya memperhatikan etika-etika berikut : mensucikan diri dari hadats dan kotoran, berpakaian yang sopan dan rapi serta berusaha berbau wewangian, berniat beribadah ketika dalam mengajarkan ilmu, menyampaikan hal-hal yang diajarkan oleh Allah (walaupun hanya

${ }^{19} \mathrm{Ibid}, \ldots$. h.158

${ }^{20}$ Suwendi, Sejarah \& Pemikiran Pendidikan Islam (Jakarta: PT. Raja Grafindo Persada, 2004), h. 154

Falasifa, Vol. 10 Nomor 2 September $2019 \mid 62$ 


\section{Pemikiran Pendidikan Islam Menurut..}

sedikit), membiasakan membaca untuk menambah ilmu pengetahuan, memberikan salam ketika masuk kedalam kelas, sebelum belajar berdo'alah untuk para ahli ilmu yang telah terlebih dahulu meninggalkan kita, berpenampilan yang kalem dan menghindarkan hal-hal yang tidak pantas dipandang mata, menghindarkan diri dari gurauan dan banyak tertawa, jangan sekali-kali mengajar dalam kondisi lapar, makan, marah, mengantuk, dan lain sebagainya, hendaknya mengambil tempat duduk yang strategis, usahakan berpenampilan ramah, tegas, lugas dan tidak sombong, dalam mengajar hendaknya mendahulukan materi yang penting dan disesuaikan dengan profesionalisme yang dimiliki, jangan mengajarkan hal-hal yang bersifat subhat yang dapat menyesatkan, perhatikan msing-masing kemampuan murid dalam meperhatikan dan jangan mengajar terlalu lama, menciptakan ketengan dalam belajar, menegur dengan lemah lembut dan baik ketika terdapat murid yang bandel, bersikap terbuka dengan berbagai persoalan yang ditemukan, berilah kesempatan pada murid yang datang terlambat dan ulangilah penjelasannya agar mudah dipahami apa yang dimaksud, dan apabila sudah selesai berilah kesempatan kepada anak didik untuk menanyakan hal-hal yang belum dimengerti. ${ }^{21}$

\section{c. Etika Guru Bersama Murid}

Guru dan murid pada dasarnya memiliki tanggung jawab yang berbeda, namun terkadang seorang guru dan murid mempunyai tanggung jawab yang sama, diantara etika tersebut adalah : berniat mendidik dan menyebarkan ilmu pengetahuan serta menghidupkan syari'at islam, menghindari ketidak ikhlasan dan mengejar keduniawian, hendaknya selalu melakukan instropeksi diri, menggunakan metode yang sudah dipahami murid, membangkitkan

\footnotetext{
${ }^{21}$ Samsul Nizar, Filsafat Pendidikan Islam, ... h.176
} 
Dhevin M.Q Agus Puspita W

semangat murid dengan memotivasinya, begitu murid yang satu dengan yang lain, memberikan latihan - latihan yang bersifat membantu, selalu memperhatikan kemapuan peserta didik yang lain, bersikap terbuka dan lapang dada, membantu memecahkan masalah dan kesulitan peserta didik, tunjukkan sikap yang arif dan tawadhu' kepada peserta didik yang satu dengan yang lain.

\section{Relevansi Pemikiran K.H. Hasyim Asy’ari dengan konteks kekinian}

Pemikiran KH. Hasyim Asy'ari sesungguhnya lebih menitik beratkan pada persoalan hati (qolb) sehingga yang menjadi hal terpenting atau modal dalam menuntut ilmu adalah niat yang tulus dan ikhlas dan mengaharapkan ridha Allah Swt, selain itu dia juga sangat menekankan penanaman akhlak dan moral terhadap siswa, jika dikaitkan dengan pendidikan sekarang maka pemikiraan $\mathrm{KH}$. Hasyim Asy'ari berhubungan erat dengan aspek afektif siswa, pada dasarnya pemikiran KH. Hasyim Asy'ari mengenai tujuan atau pun dasar yang digunakan adalah sangat tepat bahkan sangat sesuai karena menggunakan dasar Al-Qur'an dan Hadits. Karena dalam Al-Qur'an dan Hadits terwujud suatu system pendidikan yang koomperhensif yaitu kognitif, afectif dan psikomotorik.

Pemikiran KH. Hasyim Asy'ari memunculkan implikasi terhadap pendidikan Islam, diantaranya antara lain :

a. Niat yang lurus.

Seorang murid hendaknya berniat suci dalam menuntut ilmu, jangan sekalikali berniat untuk hal-hal duniawi dan jangan melecehkannya atau menyepelekannya. Sedangkan bagi guru dalam mengajarkan ilmu hendaknya meluruskan niatnya terlebih dahulu, tidak mengharapkan materi semata. Dalam hal ini terlihat, bahwa Hasyim Asy'ari lebih menekankan kepada pendidikan ruhani atau pendidikan jiwa, meski demikian pendidikan jasmani tetap diperhatikan. khususnya bagaimana mengatur makan, minum, tidur dan sebagainya. Makan dan minum tidak perlu terlalu banyak dan sederhana, seperti anjuran Rasulullah Muhammad saw. Serta jangan banyak tidur, dan jangan suka 


\section{Pemikiran Pendidikan Islam Menurut..}

bermalas-malasan. Banyakkan waktu untuk belajar dan menuntut ilmu pengetahuan, isi hari-hari dan waktu yang ada dengan hal-hal yang bermanfaat.

Etika seperti tersebut di atas, masih banyak dijumpai pada pendidikan pesantren sekarang ini, pelajar dahulu selalau berhati hati dalam mencari ilmu untuk mendapatkan keberkahan, menyukai riyadhoh untuk menambah ridho Allah akan tetapi etika seperti itu sangat langka di tengah budaya kosmopolit sekarang ini. Karena bisa kita lihat banyak pelajar sekarang yang ketika menacari ilmu suka bermalas malasan, ketika ada waktu kosong lebih banyak digunakan untuk bermain game dari pada menambah pengetahuan untuk pelajaran.

b. Tugas Dan Tanggung Jawab Murid

Dalam memahami tugas dan tanggung jawab seorang murid ketika mencari ilmu maka diperlukan kesabaran, keuletan serta kegigihan dalam belajar, seorang murid hendaknya mempunyai sifat sopan dan tawadhu' terhadap gurunya karena dengan bersifat sopan dan tawadhu tersebut seorang murid akan mendapatkan keberkahan dari ilmu yang diajarkanya.

Apabila dilihat dari realitas sekarang yang ada moralitas seorang murid terhadap guru telah mengalami kemunduran hal ini terlihat dari para pelajar tidak lagi memiliki etika yang baik. Dan kerap terjadi hal-hal yang menunjukkan bahwa rendahnya etika para pelajar terhadap guru sudah sangat parah.Guru yang mestinya dihormati dan dihargai sekarang malah dilawan dan tidak lagi disegani.

Merosotnya budaya sopan santun pelajar dipengaruhi oleh banyak faktor, baik faktor dari keluarga maupun dari lingkungan sekitar. Dan seharusnya orangtua pun turut ikut serta dalam hal ini. Sebab pelajar menghabiskan banyak waktunya di rumah dari pada di lingkungan sekolah.

Teknologi Informasi dan Komunikasi yang disalahgunakan juga menjadi pengaruh yang sangat buruk bagi perilaku pelajar zaman sekarang ini, apalagi sekarang teknologi sudah semakin canggih dan bisa memengaruhi pola pikir para pelajar.

c. Tugas dan tanggung jawab seorang Guru

Catatan yang menarik dan perlu dikedepankan dalam membahas pemikiran dan pandangan yang ditawarkan oleh Hasyim Asy'ari adalah etika atau statement 


\section{Dhevin M.Q Agus Puspita W}

yang terakhir tentang karya tulis yang harus dimiliki oleh seorang guru, hal ini sebagai wujud dari perkembangan ilmu pengetahuan yang harus selalu di update oleh setiap guru dalam disetiap masanya, dimana guru harus membiasakan diri menulis, mengarang dan meringkas, yang pada masanya jarang sekali dijumpai. Dan hal ini beliau buktikan dengan banyaknya kitab hasil karangan atau tulisan beliau.

Betapa majunya pemikiran Hasyim Asy'ari dibanding tokoh-tokoh lain pada zamannya, bahkan beberapa tahun sesudahnya. Dan pemikiran ini ditumbuh serta diangkat kembali oleh pemikir pendidik zaman sekarang ini, yaitu Harun Nasution, yang mengatakan hendaknya para dosen-dosen di Perguruan Tinggi Islam khususnya agar membiasakan diri untuk menulis.

Terlihat juga betapa beliau sangat memperhatikan sifat dan sikap serta penampilan seorang guru. Berpenampilan yang terpuji, bukan saja dengan keramahantamahan, tetapi juga dengan berpakaian yang rapi dan memakai minyak wangi. ia menawarkan agar guru bersikap terbuka, dan memandang murid sebagai subyek pengajaran bukan hanya sebagai obyek, dengan memberi kesempatan kepada murid-murid bertanya dan menyampaikan berbagai persoalan di hadapan guru.

\section{KESIMPULAN}

Pemikiran Hasyim Asy'ari dalam bidang pendidikan lebih menekankan pada etika dalam pendidikan, meski tidak menafikan beberapa aspek pendidikan lainnya. Dalam hal ini banyak dipengaruh dengan keahliannya pada bidang Hadits, dan pemikirannya dalam bidang tasawuf dan fiqih yang sejalan dengan teologi al Asy'ari dan al Maturidi. Juga searah dengan pemikiran al-Ghazali, yang lebih menekankan pada pendidikan rohani. Misalnya belajar dan mengajar harus dengan ikhlas, semata-mata karena Allah, bukan hanya untuk kepentingan dunia tetapi juga untuk kebahagian di akhirat. Dan untuk mencapainya seseorang yang belajar atau mengajar harus punya etika, punya adab dan moral, baik murid ataupun guru sendiri.

K.H. Muhammad Hasyim Asy'ari memandang pendidik sebagai pihak yang sangat penting dalam pendidikan. Baginya, guru adalah sosok yang mampu mentransmisikan ilmu pengetahuan disamping pembentuk sikap dan etika peserta didik.

Falasifa, Vol. 10 Nomor 2 September $2019 \mid 66$ 
Pemikiran Pendidikan Islam Menurut..

\section{DAFTAR PUSTAKA}

Ahmad D. Marimba, Pengantar Filsafat Pendidikan Islam, (Bandung: al Ma'arif, 2003).

Asma Hasan Fahmi, Sejarah dan Filsafat Pendididkan Islam, (Jakarta: Bulan Bintang,2008).

Dewan Redaksi, Ensiklopedia Islam, (Jakarta, PT. Ichtiar Baru Van Hoeve, 1997).

Haidar Putra Daulay, Sejarah Pertumbuhan dan Pembaruan Pendidikan Islam di Indonesia, (Jakarta: Kencana, 2007)

Khairul Fathoni, Muhammad Zen, NU Pasca Khittah, Porspek Ukhuwah Dengan Muhammadiyah, (Yogyakarta: Media Widya Mandala, 1992).

Lathiful Khuluq, Kebangkitan Ulama, Biografi K.H.Hasyim Asy'ari, (Yogyakarta: LKIS, 2000).

Maksum Machfoedz, Kebangkitan Ulama dan Bangkitnya Ulama, (Surabaya: Yayasan Kesatuan Umat, 1982).

Samsul Nizar, Filsafat Pendidikan Islam, (Jakarta: Ciputat Press, 2002).

Suwendi, Sejarah \& Pemikiran Pendidikan Islam (Jakarta: PT. Raja Grafindo Persada, 2004)

Pradjata Dirdjosanjoto, Memelihara Umat, Kiai Pesantren-Kiai Langgar di Jawa, (Yogyakarta: UKIS, 1999).

Zamakhsyari Dhofier, Tradisi Pesantren, (Jakarta: LP3ES, 1982). 